\title{
https://doi.org/10.46813/2021-133-011 \\ DECAY WIDTH MODELING OF HIGGS BOSON WITHIN THDM MODEL
}

\author{
T.V. Obikhod, E.A. Petrenko \\ Institute for Nuclear Research, NAS of Ukraine, Kyiv, Ukraine \\ E-mail: obikhod@kinr.kiev.ua
}

As part of the search for new physics beyond the Standard Model, we chose the determination of the Higgs boson decay width as one of the least experimentally determined values. The decay widths into the four fermions of the lightest and heaviest CP-even Higgs bosons of the THDM model were calculated, taking into account QCD and electroweak corrections in the NLO approximation. To achieve this goal, the program Monte Carlo Prophecy $4 \mathrm{f}$ with special scenarios of parameters, 7B1 and 5B1 were used. It was found that the decay width of the heavier CPeven Higgs boson $\mathrm{H}$ differs from $\mathrm{H}_{S M}$ by 1227.93 times and changes to a negative value when deviating from the standard scenarios. Scale factors $\mathrm{k}_{Z}{ }^{2}$ and $\mathrm{k}_{W}{ }^{2}$ showed the predominance of the associated with $\mathrm{Z}$ boson production cross section of $\mathrm{CP}$-even Higgs boson over the associated with $\mathrm{W}$ production cross section.

PACS: 02.70.-c, 11.80.-m, 13.85.Hd

\section{INTRODUCTION}

In light of the latest experimental data on the searches for new physics beyond the Standard model (SM). Higgs boson remains the only candidate for a window into new physics [1]. This task is related to the experimental study and theoretical predictions of the properties of the Higgs boson, such as Higgs cross sections, the partial decay width and with coupling measurements, $\xi$. The crucial role for the investigation of the of the Higgs boson properties is played by the Higgs branching ratios and decay widths [2]. The Higgs particle is a massive scalar boson with zero spin, no electric charge, and no colour charge is very unstable, decaying immediately into other particles. As all the channels of decay of the Higgs boson as well as possible new particles with certain masses have not yet been studied, there are uncertainties in the properties of the coupling constants and, accordingly, in the decay width of this particle. This fact is demonstrated by the deviation of the predicted SM Higgs decay width of about $4.07 \cdot 10^{-3} \mathrm{GeV}$ from the experimental data, which are presented in Table $1[3,4]$.

Run 1 observed (expected) direct $95 \% \mathrm{CL}$
constraints on the width of the $125 \mathrm{GeV}$
resonance from fits to the $\gamma \gamma$ and $\mathrm{ZZ}$ mass spectra.
The CMS measurement from the 4 l mass
line-shape was performed using Run 2 data
\begin{tabular}{|l|c|c|}
\hline Experiment & $M_{\gamma \gamma}$ & $M_{4 l}$ \\
\hline ATLAS & $<5.0(6.2) \mathrm{GeV}$ & $<2.6(6.2) \mathrm{GeV}$ \\
\hline CMS & $<2.4(3.1) \mathrm{GeV}$ & $<1.1(1.6) \mathrm{GeV}$ \\
\hline
\end{tabular}

The purpose of our paper is to calculate decay widths of lightest, h, and CP-even, $\mathrm{H}$, Higgs bosons of Two Higgs doublet model (THDM) [5] as well as the value of the deviation from SM of the sum of the partial Higgs decay widths compared to the SM, $\kappa_{H}^{2}$, through computer modeling with the help of Monte Carlo program Prophecy 4f 3.0 [6].

\section{THE CALCULATIONS OF DECAY WIDTH AND SCALE FACTOR}

The SM predicts a very small width of about $4 \mathrm{MeV}$ for a $126 \mathrm{GeV}$ Higgs boson. And the error of the energy measurement at the Large Hadron Collider is hundreds of times greater, on the order of $1 \mathrm{GeV}$, and it will not be possible to significantly reduce it. As a result, measuring the width of the Higgs boson directly is unrealistic. However, it is possible to accumulate data on the production and decay of the Higgs boson at significantly higher energies - not in the vicinity of $126 \mathrm{GeV}$, but, say, above $300 \mathrm{GeV}$ [7]. This process will look like the birth and decay of a virtual Higgs boson. It is, of course, strongly weakened in comparison with the main process at the resonance peak, but it can be quite measurable.

As THDM model predicts the existence of five Higgs bosons, we will carry out our calculations for two bosons: lightest Higgs boson, h and CP-even Higgs boson, $\mathrm{H}$ as the analog of virtual Higgs boson described above. Thus, the idea of theorists - to accumulate data on the production and decay of the Higgs boson at significantly higher energies can be realized. The efficiency of this method can be estimated by comparing the calculations of decay widths for the lightest and heaviest bosons.

The precise experimental investigation of the Higgs boson and theoretical searches for deviations from the predictions of SM requires precise Monte Carlo computer modeling. Prophecy $4 \mathrm{f}$ computes the inclusive partial decay widths and differential distributions of the decay products, where unweighted events for leptonic final states are provided. The advantage of the Prophecy 4f program is that it allows the calculations for the Higgs decays into four fermions including full electroweak and QCD next-to-leading order (NLO) corrections with interference contributions between different WW/ZZ channels, and all off-shell effects of intermediate $\mathrm{W} / \mathrm{Z}$ bosons. 
We'll consider the processes, LO Feynman diagram of which is in the form of Fig.

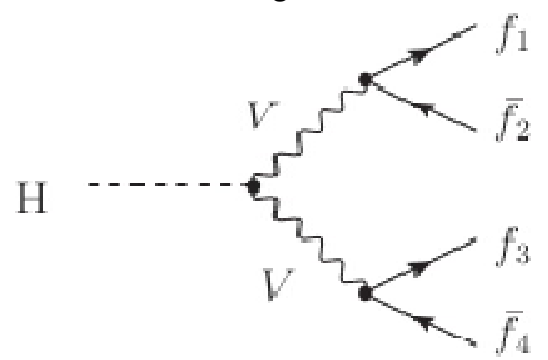

Generic diagram for decay of $H \rightarrow 4 f$ where $V=W, Z$, from $[6]$

The total state width of Higgs boson is equal to the sum of the partial channel widths [6]:

$$
\Gamma_{H \rightarrow 4 f}=\Gamma^{\text {total }}=\Gamma^{\text {leptonic }}+\Gamma^{\text {semi-leptonic }}+\Gamma^{\text {hadronic }} \text {, }
$$

The total width can be presented via $\mathrm{ZZ}$, WW decays and their interference:

$\Gamma_{H \rightarrow 4 f}=\Gamma_{H \rightarrow W * W \rightarrow A f}+\Gamma_{H \rightarrow Z^{*} Z^{*} \rightarrow 4 f}+\Gamma_{W W / Z Z-i n t}$, where the components are defined in terms of specific final states:

$$
\begin{aligned}
& \Gamma_{H \rightarrow W * W * 4 y}=
\end{aligned}
$$

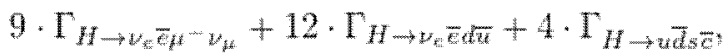

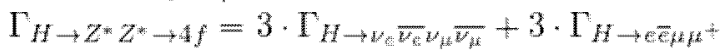

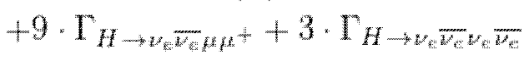

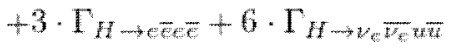

$$
\begin{aligned}
& +9 \cdot \Gamma_{H \rightarrow u_{e} \overline{p_{e}} d a}+6 \cdot \Gamma_{U \rightarrow \text { uree }}
\end{aligned}
$$

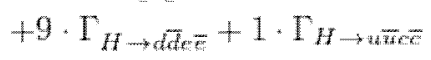

$$
\begin{aligned}
& +3 \cdot \Gamma_{H \rightarrow \text { hs }}+6 \cdot \Gamma_{H \rightarrow \text { घas }}
\end{aligned}
$$

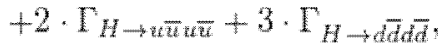

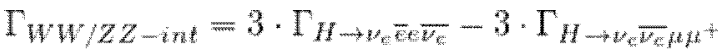

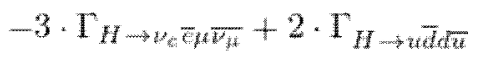

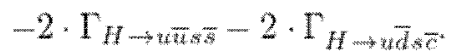

Using scenarios obtained from the experimental measurements [8] we presented the calculated NLO results on the four-fermion decays of light $\mathrm{CP}$-even Higgs boson, h, Table 2.

Decay widths of lightest Higgs boson, $h$

Table 2

\begin{tabular}{|c|c|c|c|c|}
\hline & $\begin{array}{c}\text { Full decay width } \\
\text { of lightest Higgs } \\
\text { boson, h, MeV }\end{array}$ & $\Gamma \rightarrow \mathrm{WW}$ & $\Gamma \rightarrow \mathrm{ZZ}$ & $\Gamma^{\mathrm{int}}$ \\
\hline 5-B1 & 0.92852 & 0.8326 & 0.1007 & -0.00478 \\
\hline 7-B1 & 0.93026 & 0.8311 & 0.104 & -0.00484 \\
\hline
\end{tabular}

We also perform calculations of CP-even Higgs boson with the different parameters presented below, in Table 3 and decay widths, Table 4.

Table 3

THDM input parameters

\begin{tabular}{|l|l|l|l|c|c|c|}
\hline & $M_{H}, \mathrm{GeV}$ & $M_{H^{+}}, \mathrm{GeV}$ & $M_{A}, \mathrm{GeV}$ & $\lambda_{5}$ & $\tan \beta$ & $c_{\alpha \beta}$ \\
\hline I & 360 & 690 & 420 & -1.9 & 4.5 & 0.15 \\
\hline II & 600 & 690 & 690 & -1.9 & 4.5 & 0.15 \\
\hline
\end{tabular}

Table 4

Decay width of $C P$-even Higgs boson, $H$

\begin{tabular}{|c|l|l|c|}
\hline $\begin{array}{c}\text { Full decay width } \\
\text { of lightest Higgs } \\
\text { boson, } \mathrm{h}, \mathrm{MeV}\end{array}$ & $\Gamma \rightarrow \mathrm{WW}$ & $\Gamma \rightarrow \mathrm{ZZ}$ & $\Gamma^{\text {int }}$ \\
\hline-54.487 & -71.47 & 17.203 & -0.22 \\
\hline 1176.36 & 789.98 & 385.74 & 0.64 \\
\hline
\end{tabular}

The calculations of SM Higgs boson decay width give us the following result, Table 5

Table 5

Decay width of SM Higgs boson, $H_{S M}$

\begin{tabular}{|c|c|c|c|}
\hline $\begin{array}{c}\text { Full decay } \\
\text { width } \mathrm{h}, \mathrm{MeV}\end{array}$ & $\Gamma \rightarrow \mathrm{WW}$ & $\Gamma \rightarrow \mathrm{ZZ}$ & $\Gamma^{\text {int }}$ \\
\hline 0.958 & 0.858 & 0.10724 & -0.00724 \\
\hline
\end{tabular}

In the absence of beyond SM (BSM) Higgs decay modes, total scale factor $\kappa_{H}^{2}$ is the value of the deviation of the sum of the partial Higgs decay widths compared to the SM total width $\Gamma_{H}^{S M}$ :

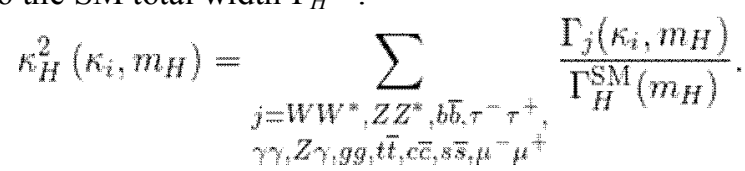

Since the identification of four leptons is the most detectable decay mode in comparison with other decay channels, the optimal direction of the search for new physics will be finding and comparison of the factor $\kappa_{H}{ }^{2}$ for the decays of two Higgs bosons - the lightest and the heaviest one into $W W$ or $Z Z$ bosons. So, the scale factor $\kappa_{H}{ }^{2}$ in this case is the following:

$$
\kappa_{H}^{2}\left(\kappa_{i}, m_{H}\right)=\sum_{j=W W^{*}, Z Z^{*}} \frac{\Gamma_{j}\left(\kappa_{i}, m_{H}\right)}{\Gamma_{H}^{\mathrm{SM}}\left(m_{H}\right)} .
$$
$\kappa_{Z}^{2}$ :

It is also interesting to calculate scale factors $\kappa_{W}^{2}$ and

$$
\frac{\Gamma_{W W^{*}}}{\Gamma_{W W^{*}}^{\mathrm{SM}}}=\kappa_{W}^{2}, \frac{\Gamma_{Z Z^{*}}}{\Gamma_{Z Z^{*}}^{\mathrm{SM}}}=\kappa_{Z}^{2},
$$

which allow probing for BSM contributions in the loops for each channel separately. Moreover, these factors make it possible to calculate the deviations from the SM of the associated production cross sections in accordance with the formulas:

$$
\frac{\sigma_{W H}}{\sigma_{W H}^{\mathrm{SM}}}=n_{W}^{2}, \frac{\sigma_{Z H}}{\sigma_{Z H}^{\mathrm{SM}}}=n_{Z}^{2}
$$

The results of our calculations are performed in the Table 6 .

Table 6

Scaling factors of two Higgs bosons

\begin{tabular}{|l|l|l|l|l|l|}
\hline Boson & Scenario & $\kappa_{W}{ }^{2}$ & $\kappa_{Z}{ }^{2}$ & $\begin{array}{c}\kappa_{H}{ }^{2} \\
\text { w/o int }\end{array}$ & $\begin{array}{c}\kappa_{H}{ }^{2} \\
\text { wint }\end{array}$ \\
\hline $\mathrm{h}$ & 5-B1 & 0.97 & 0.939 & 0.967 & 0.969 \\
\hline $\mathrm{h}$ & $7-\mathrm{B} 1$ & 0.968 & 0.97 & 0.969 & 0.971 \\
\hline $\mathrm{H}$ & $\mathrm{II}$ & 921 & 3597 & 1218 & 1228 \\
\hline
\end{tabular}

From the comparison of the data from Table 6 we see the slight change in $\kappa_{H}^{2}$ factor for 5-B1 and 7-B1 scenarios and huge increase compared to $\mathrm{SM}$ one for scenario II. Moreover, we can see the increasing of $\kappa_{H}{ }^{2}$ factor for all scenarios with inclusion of interference. The BSM contributions in the loops for WW channel are larger in 5-B1 scenario but for 7-B1 scenario the lar- 
ger contribution in the loops are for $\mathrm{ZZ}$ channel. Therefore, the chose of renormalization schema is also essential to the final result. The sharp jump in the $\kappa_{H}^{2}$ factor of CPeven Higgs boson indicates about significant deviation from the SM and the possible existence of CP-even Higgs boson with a mass from scenario 7-B1. The difference in factor $\kappa_{Z}^{2}$ compared to $\kappa_{W}{ }^{2}$ by almost four times indicates the predominance of the associated with $\mathrm{Z}$ boson production cross section of CP-even Higgs boson over the associated with $\mathrm{W}$ production cross section.

\section{CONCLUSIONS}

The searches for BSM physics are connected with studying of Higgs boson properties. The way of the realization of this purpose is connected with decay widths measurements and theoretical predictions of Higgs boson properties. The most perspective and convenient Higgs boson decay channel into four fermions is one of the interesting way of its investigation. For the precise measurements of decay width in the paper is proposed THDM model. We have considered lightest and CP-even heavier Higgs bosons, $\mathrm{h}$ and $\mathrm{H}$ correspondingly and modeled their decay widths into four fermions with the help of Monte Carlo program Prophecy 4f 3.0. The results of our calculations led us to the following conclusions connected with the searches of deviations from SM:

- decay widths of lightest Higgs boson, $\mathrm{h}$ and $\mathrm{H}_{S M}$ almost do not differ from each other;

- the scale factor $\kappa_{H}{ }^{2}$ of CP-even Higgs boson, $\mathrm{H}$ equal to 1228 ;

- the calculations of decay widths strongly depend on the parameter space and can take negative values as the masses of the CP-even and CP-odd Higgs bosons decrease by almost two times from the parameters of the B1 scenario;

- account in calculating the interference leads to an insignificant increase in decay widths;

- the difference in factor $\kappa_{Z}^{2}$ compared to $\kappa_{W}^{2}$ by almost four times indicates the predominance of the associated with $\mathrm{Z}$ boson production cross section of $\mathrm{CP}$-even
Higgs boson, $\mathrm{H}$ over the associated with $\mathrm{W}$ production cross section.

- BSM contributions in the loops for WW and ZZ channels vary depending on renormalization schema.

\section{REFERENCES}

1. The higgs boson as a probe for new physics // URL: https://ep-news.web.cern.ch/higgs-boson-probenew-physics. Accessed: 2019-06-18.

2. M. Spira. Higgs boson production and decay at hadron colliders // Progress in Particle and Nuclear Physics. 2017, v. 95, p. 98-159.

3. ATLAS Collaboration. Measurement of the higgs boson mass from the $h \rightarrow \gamma \gamma$ and $h \rightarrow z Z^{*} \rightarrow 4 \ell$ channels in $p p$ collisions at center-of-mass energies of 7 and $8 \mathrm{TeV}$ with the atlas detector// Phys. Rev. D. 2014, v. 90, p. 052004.

4. CMS Collaboration. Measurements of properties of the Higgs boson decaying into four leptons in pp collisions at sqrts $=13 \mathrm{TeV} / /$ Tech . Rep. CMS-PASHIG-16-041, CERN, Geneva, 2017.

5. G. Branco, P. Ferreira, L. Lavoura, M. Rebelo, M. Sher, and J.P. Silva. Theory and phenomenology of two-Higgs-doublet models // Physics Reports. 2012, v. 516, № 1, p. 1-102.

6. A. Denner, S. Dittmaier, and A. Müuck. Prophecy $4 \mathrm{f}$ 3.0: A monte carlo program for higgs-boson decays into four-fermion final states in and beyond the standard model // Computer Physics Communications. 2020, v. 254, p. 107336.

7. Novyj metod pozvolil nalozhit rekordnoe ogranichenie na vremya zhizni xiggsovskogo bozona // URL: https://elementy.ru/novosti_nauki/432235. Accessed: 2014-04-17.

8. A. Denner, S. Dittmaier, and J.-N. Lang. Renormalization of mixing angles // Journal of High Energy Physics. 2018, v. 2018, p. 104.

Article received 06.04.2021

\section{МОДЕЛИРОВАНИЕ ШИРИНЫ РАСПАДА БОЗОНА ХИГГСА В РАМКАХ ТНDМ-МОДЕЛИ}

\section{T.В. Обиход, Е.А. Петренко}

В рамках поисков новой физики за пределами стандартной модели нами были выбраны определения ширины распада бозона Хиггса, как одно из наименее экспериментально определенного значения. Рассчитана ширина распадов на четыре фермиона легкого и тяжелого СР-парного бозонов Хиггса модели THDM с учетом КХД и электрослабых поправок в NLO-приближении. Для реализации этой цели была использована программа Монте-Карло Prophecy 4f со сценариями пространства параметров 7B1 и 5В1. Выявлено, что ширина распада тяжелого СР-парного бозона Хиггса Н отличается от $\mathrm{H}_{S M}$ в 1227,93 раза и меняется к отрицательному значению при отклонении от стандартных сценариев. Масштабные факторы $\mathrm{k}_{Z}^{2}$ и $\mathrm{k}_{W}^{2}$ показали преобладание связанного с Z-бозоном сечения рождения CР-парного бозона Хиггса Н над ассоциированным с W-сечением.

\section{МОДЕЛЮВАННЯ ШИРИНИ РОЗПАДУ БОЗОНА ХІГГСА В РАМКАХ ТНDМ-МОДЕЛІ Т.В. Обіход, С.О. Петренко}

У рамках пошуків нової фізики за межами стандартної моделі нами було обрано визначення ширини розпаду бозона Хіггса, як одного з найменш експериментально визначених значень. Розрахована ширина розпадів на чотири ферміони найлегшого і важчого СР-парного бозонів Хіггса моделі ТНDM з урахуванням КХД і електрослабких поправок у NLO-наближенні. Для реалізації цієї цілі було використано програму Монте-Карло Prophecy 4f зі сценаріями простору параметрів 7B1 та 5В1. Виявлено, що ширина розпаду важчого СР-парного бозона Хіггса Н відрізняється від $\mathrm{H}_{S M}$ у 1227,93 рази і змінюється до від’ємного значення при відхиленні від стандартних сценаріїв. Масштабні фактори $\mathrm{k}_{Z}^{2} \mathrm{i}_{W}^{2}$ показали переважання пов'язаного 3 Zбозоном перерізу народження СР-парного бозона Хіггса Н над асоційованим з W-перерізом. 